\title{
Bovine colostrum: Postpartum changes in fat globule size distribution and fatty acid profile
}

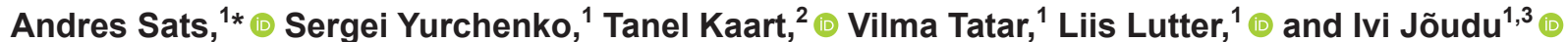 \\ ${ }^{1}$ Chair of Food Science and Technology, Estonian University of Life Sciences, Kreutzwaldi 1 Tartu Estonia 51006 \\ ${ }^{2}$ Chair of Animal Breeding and Biotechnology, Estonian University of Life Sciences, Kreutzwaldi 1 Tartu Estonia 51006 \\ ${ }^{3}$ ERA Chair for Food (By-) Products Valorisation Technologies of the Estonian University of Life Sciences (VALORTECH), \\ Kreutzwaldi 1 Tartu Estonia 51006
}

\section{ABSTRACT}

Although "zero waste" valorization concepts are gaining increasing attention, colostrum, a byproduct of milk production, remains underused due to technological challenges. Information about the fat fraction and the size of fat globules is needed to address these challenges, but such information is currently lacking. This study aimed to fill this gap in the knowledge by measuring the size distribution of bovine colostrum fat globules $(\mathrm{CFG})$ and analyzing its relationships with postpartum milkings, parity, and fatty acids (FA) profile. Four sequential postpartum colostrum samples were collected from 44 cows and analyzed for the abovementioned parameters. The results indicated that CFG size increases almost twice during postpartum milkings (from $\sim 5$ to $\sim 10 \mu \mathrm{m}$ ), whereas lactation has little, if any, effect on CFG size. The FA profile analyses showed that the content of most FA in the fourth postpartum milking was different from the previous milkings. The correlation analyses between CFG size and FA profile also demonstrated that the fourth milking was clearly distinguishable from the first 3 postpartum milkings. For example, the saturated FA content from the first 3 milkings had a positive correlation with smaller CFG (and a negative correlation with larger CFG), whereas the fourth milking demonstrated no correlations. Based on these CFG size and FA profile analyses, the results of this study suggest that the first 3 postpartum milkings can be considered as colostrum, whereas the fourth milking represents transition milk. Information about CFG size distribution enables modification of the FA profile of colostrum products and the ability to create better valorization technologies for colostrum-based food and feed supplements.

Received March 8, 2021.

Accepted January 10, 2022.

*Corresponding author: Andres.Sats@emu.ee
Key words: colostrum, fat globule size, polyunsaturated fatty acid, transition milk, parity

\section{INTRODUCTION}

Rapid human population growth and increasing food demands have made the "zero waste" and "full valorization" production concepts critical. Together with other essential nutrients, the need for animalorigin fatty acids (FA) is increasing. Due to improved breeding and farming practices, the individual milk production of cows has increased over the past centuries, whereas the consumption of milk by newborn heifers has remained the same. As a result, large-scale milk production inevitably leads to the production of considerable amounts (about $1 \%$ of annual milk production) of colostrum and transition milk. Colostrum composition differs significantly from milk (Playford and Weiser, 2021), containing higher levels of proteins (especially immunoglobulins; Kehoe et al., 2007; Sats et al., 2020), vitamins, minerals (Kehoe et al., 2007; Duplessis et al., 2015), antioxidants (Przybylska et al., 2007), and PUFA (Contarini et al., 2014). Due to the thermal sensitivity of proteins and FA profile-related cream separation issues (e.g., fat melting point), the utilization of colostrum using milk valorization technologies is complicated. As a result, traditional dairy industries do not collect colostrum and transition milk for further processing.

Colostrum is a valuable source of proteinaceous bioactive factors and essential nutrients (Playford and Weiser, 2021) that are mostly marketed as protein products. At the same time, bovine colostrum is also a source of PUFA (Contarini et al., 2014), which are associated with cancer prevention (Baum et al., 2012). The FA profile of colostrum differs from that of mature milk (Laakso et al., 1996; Contarini et al., 2014). However, despite an increasing number of studies addressing colostrum, its FA profile has gained little attention.

The diameter of milk fat globules (MFG) determines the thermal and physiological properties of 
milk (Michalski et al., 2004) and its lipid composition (Michalski, et al., 2005). Moreover, MFG size affects the physicochemical and functional properties of dairy products (Logan et al., 2014; Edén et al., 2016) as well as the digestion and bioavailability of FA (Garcia et al., 2014; Singh and Gallier, 2017; Uken et al., 2021). The colostrum fat fraction also plays an important role from a herd reproduction point of view, as energy reserves of the newborn calves are scarce, and fat consumption increases their thermoregulation ability (Murray and Leslie, 2013). In this regard, the FA composition and size distribution of fat globules are essential parameters that determine the effective metabolism of fat. Using "whole milk," it has been shown that these 2 parameters, MFG size and composition, are related (Martini et al., 2016; Couvreur and Hurtaud, 2017). However, there is currently no information about the size distribution of bovine colostrum fat globules (CFG).

For a more complete understanding about colostrum component size distribution, studies need to focus simultaneously on multiple parameters (Sats et al., 2020). In this study, the aim was to describe the bovine colostrum FA profile and CFG size. In addition, the relationships between FA profile, CFG size distribution, parity, and immediate postpartum milkings were analyzed.

\section{MATERIALS AND METHODS}

\section{Sampling}

Colostrum samples were collected from 44 Holstein cows from the experimental farm of the Estonian University of Life Sciences between 2015 and 2017. The average $( \pm$ SE) milk, fat, and protein production of previous lactation of sampling cows was 9,524 \pm 159.2 , $372 \pm 6.2$, and $313 \pm 4.6 \mathrm{~kg}$, respectively. The average lengths of the lactation and dry periods were $300 \pm 1.1$ and $60 \mathrm{~d}$, respectively. All cows included in this study were in good health. To prevent suckling, calves were separated from dams. Cows were milked with a portable milking machine 30 to 120 min after calving and thereafter twice per day at regular milking times (at 12 $\pm 1 \mathrm{~h}$ intervals). Four sequential postpartum samples were collected from each cow $(\mathrm{n}=4 \times 44=176)$. After milking, the colostrum of each animal was stirred, and the sample $(50 \mathrm{~mL})$ was collected. Sampled cows were selected according to their lactation number (10 in the first, 9 in the second, 10 in the third, 8 in the fourth, 3 the in fifth, 2 the in sixth, and 2 in the seventh). Two cows were sampled in $2 \mathrm{yr}$ ( 1 in its fourth and fifth and 1 in its fifth and sixth lactations). Samples were frozen at $-20^{\circ} \mathrm{C}$ and stored. During the dry period and after calving, cows were fed ad libitum. Daily diets
Table 1. The ingredients, chemical composition, and nutritional value in feed during the dry period and after calving

\begin{tabular}{lcc}
\hline Item & Dry period & After calving \\
\hline Ingredient, g/kg & & \\
Grass-clover silage & 687 & 696 \\
Barley & 229 & 232 \\
Heat treated rapeseed cake & 62 & 63 \\
Mineral-vitamin feed & 9 & 9 \\
Anion mineral feed & 13 & \\
Chemical composition, g/kg & & 154 \\
CP & 154 & 35 \\
Crude fat & 35 & 211 \\
Crude fiber & 211 & 10.3 \\
Nutritional value & & 90 \\
ME, MJ & 10.3 & \\
MP, g/kg & 90 & \\
\hline
\end{tabular}

were based on hay and grass silage with the addition of a concentrate feed (barley flour, rapeseed cake) and Rindavital VK mineral feed (Schaumann Agri International $\mathrm{GmbH}$ ). The ingredients, chemical composition, and nutritional value of the feed during the dry period and after calving are presented in Table 1 . The farming conditions were constant in all lactations.

\section{Determination of FA Profile}

Extraction of FA was performed according to the boron trifluoride method described by Yurchenko et al. (2016). Fatty acid methyl esters were analyzed on a Varian 3900 gas chromatograph equipped with a flame ionization detector and autosampler CP-8400. Chromatographic separation of FAME was performed using a Supelco ionic liquid column SLB-IL111 (100m $\times 0.25 \mathrm{~mm}$ i.d., $0.20 \mu \mathrm{m}$ film thickness). Tridecanoic acid methyl ester (C13:0) as internal standard and CRM47885 standard mixture as external standard were used. A more detailed method description has been described by Yurchenko et al. (2018).

The following sums and indices were calculated: SFA, MUFA, PUFA, atherogenic index, desaturase index (DI), and ratio of n-6 and n-3 FA (n-6/n-3). The atherogenic index was calculated as has been proposed by Ulbricht and Southgate (1991) as follows: atherogenic index $=(\mathrm{C} 12: 0+4 \times \mathrm{C} 14: 0+\mathrm{C} 16: 0) /(\mathrm{MUFA}+\mathrm{n}-6$ $+\mathrm{n}-3)$, and $\mathrm{n}-6 / \mathrm{n}-3$ as n- $6 / \mathrm{n}-3=(\mathrm{C} 18: 2 \mathrm{n}-6+\mathrm{C} 20: 2 \mathrm{n}$ $-6+\mathrm{C} 18: 3 \mathrm{n}-6) / \mathrm{C} 18: 3 \mathrm{n}-3$. The DI was defined as follows: product of desaturase/substrate of desaturase and calculated for 3 pairs of FA (DI14 = C14:1 cis-5/C14:0; DI16 = C16:1 cis-7/C16:0; DI18 = C18:1 cis-9/C18:0).

\section{Size Distribution of Fat Globules}

Size distribution was determined with a laser diffraction analyzer (Malvern Mastersizer 3000, Malvern 
Instruments Ltd.). Samples were frozen at $-20^{\circ} \mathrm{C}$ after collection to store samples until more detailed measurements (below). Preliminary experiments in our laboratory have confirmed that freezing-thawing cycles have no significant effect on milk fat globule size distribution when measured by the Mastersizer 3000 (Table 2). Thawed colostrum samples were gently vortexed before transfer into an analyzer dispersion tank containing reverse osmosis water (grade 2, conductivity 0.055 $\mu \mathrm{S} / \mathrm{cm}$ ). The material (lipid, refractive index 1.6) and dispersant (water, refractive index 1.33) were selected as proposed by Mastersizer software, and the speed of the stirrer was $2,000 \mathrm{rpm}$. The size distribution of the fat globules was measured after sufficient amount of sample was added to obtain an obscuration of 5 to $8 \%$. Size by volume distribution-based percentiles (Dv10 as the first decile, Dv50 as the median, Dv90 as the last decile), means ( $\mathrm{D}[4,3]$, volume moment mean; $\mathrm{D}[3,2]$ surface moment mean), and mode were derived from Mastersizer software. $\mathrm{D}[4,3]$ and $\mathrm{D}[3,2]$ were defined by the following equation:

$$
\mathrm{D}[k, z]=\frac{\sum N_{i} d_{i}^{k}}{\sum N_{i} d_{i}^{z}}
$$

where $N_{i}$ is the number of globules in a size class of $d_{i}, k$ $=4$ and $z=3$ for $\mathrm{D}[4,3]$, and $k=3$ and $z=2$ for $\mathrm{D}[3,2]$.

\section{Statistical Analyses}

For statistical analyses, the bovine CFG size distribution in the form of frequency tables obtained from Malvern Mastersizer 3000 software were used. In these tables, CFG sizes from 0.1 to $3,500 \mu \mathrm{m}$ were divided into 100 intervals on a $\log _{10}$ scale, and the CFG volume percentage in each size interval was presented. Therefore, 100 relative frequencies of CFG size groups that summed $100 \%$ were obtained for each sample. The mean CFG size distributions for postpartum milkings and lactation numbers were obtained by calculating the mean frequencies of CFG size intervals by milkings and lactation numbers. Additionally the bovine CFG size mode, $\mathrm{D}[4,3], \mathrm{D}[3,2]$, first decile, median, and last decile were evaluated for each sample from Malvern Mastersizer 3000 software.

The postpartum milking and lactation numbers were considered as categorical factors, and their effects on bovine CFG size first decile, median, and last decile and on the colostrum FA content and FA sums and ratios were analyzed by fitting a general linear mixed model. In this model, fixed effects of the above factors, their interactions, and random effect of cow were considered. The marginal means (alias least squares means with $95 \%$ confidence interval) were estimated and compared by milkings and lactation numbers, applying the Tukey test for multiple testing. The magnitude of the cow effect was estimated using the intraclass correlation coefficient. Initially analyses were made with 5 parity groups. However, as there were no systematic differences between later lactations, especially in bovine colostrum fat globule size distribution, it was decided to consider all later lactations (>3) together.

The relationships between CFG size and colostrum FA content were studied with Pearson correlation analysis. First, the correlation coefficients between median CFG size and FA content were calculated at each milking and lactation combination. Second, to study the dynamics of the relationships over the whole CFG size distribution, the correlation coefficients between FA content and CFG frequency in each size interval were calculated. To discover common CFG size distribution patterns, principal component analysis (PCA) was performed. To analyze to what extent these patterns reflected the differences between milkings and lactation numbers, general linear mixed models with principal components as dependent variables; milkings, lactation numbers, and their interactions as fixed effects; and cow as a random effect were fitted. The relationships between PCA patterns and colostrum FA content were studied with Pearson correlation analysis. In correlation analysis and PCA, only CFG size distribution in the interval of 1 to $100 \mu \mathrm{m}$ was used.

All statistical analyses (significance was declared at $P \leq 0.05)$ were performed, and all figures were con-

Table 2. Mean (SE) milk fat globule size $(\mu \mathrm{m})$ first volume distribution decile (Dv 10), median (Dv 50), last decile (Dv 90), and D[4,3] (volume moment mean), according to number of freeze-thaw cycles

\begin{tabular}{lllll}
\hline $\begin{array}{l}\text { Freeze-thaw cycles, } \\
\text { count }\end{array}$ & Dv 10 & Dv 50 & Dv 90 & D [4,3] \\
\hline 0 & $2.20(0.03)$ & $4.21(0.06)$ & $6.98(0.15)$ & $4.35(0.08)$ \\
2 & $2.15(0.02)$ & $4.09(0.03)$ & $6.69(0.06)$ & $4.38(0.11)$ \\
4 & $2.16(0.02)$ & $4.10(0.03)$ & $6.71(0.06)$ & $4.58(0.27)$ \\
$P$-value & 0.213 & 0.077 & 0.074 & 0.157 \\
\hline
\end{tabular}

${ }^{1} P$-value indicates the statistical significance of the effect of freeze-thaw cycles according to repeated-measures ANOVA ( $\mathrm{n}=6 \times 3=18,6$ samples and 3 cycles). 
structed with R version 4.0.3 (https://www.r-project .org/). We used the packages 'car', 'Ime4', 'emmeans', and 'multcompView' for modeling, and we used the package 'ade4' for PCA.

\section{RESULTS AND DISCUSSION}

\section{Fat Globule Size}

CFG Size Distribution. The colostrum size distribution consisted of 2 subdistributions, with the majority being around $10 \mu \mathrm{m}$ and the minority (barely noticeable subdistribution) being $<0.5 \mu \mathrm{m}$ (Figure $1 \mathrm{~A})$. The CFG size recorded in this study was larger than the mean MFG size $(3-6 \mu \mathrm{m})$ reported in previous studies (Ménard et al., 2010; Logan et al., 2014; Jaakamo et al., 2019). However, our findings were in line with those of Michalski et al. (2005), who studied human breast milk within first postpartum days and reported large $(\sim 9 \mu \mathrm{m})$ and small $(\sim 0.1 \mu \mathrm{m})$ size populations similarly (Figure 1A). They suggested that both subdistributions represent fat globules. Unlike Michalski et al. (2005), we did not dissociate the casein micelles. Therefore, in our case, the smaller subdistribution $(<0.5 \mu \mathrm{m}$, Figure 1A) might have also represented casein micelles as the diameter of casein micelles is between 0.15 and $0.2 \mu \mathrm{m}$ (Mootse et al., 2014). Nevertheless, because the $<0.5 \mu \mathrm{m}$ subdistribution is barely noticeable (Figure 1A) and far smaller than the first decile of size distribution (Table 3), we argue that it has no sizing effect.

Postpartum Milking. In samples of first postpartum milking, the CFG median size recorded in this study was in a similar range $(4.5-5.5 \mu \mathrm{m})$ to the MFG $(3-6 \mu \mathrm{m})$ reported in previous studies (Lopez et al., 2011; Fleming et al., 2017; Jaakamo et al., 2019). During the subsequent 3 postpartum milkings, the CFG diameter almost doubled (Figure 1; Table 3), reaching $10 \mu \mathrm{m}$ at the fourth postpartum milking. The effect of milking was significant $(P<0.001)$ in all size-describing parameters (Dv10, Dv50, Dv90, D[4,3], D[3,2] and mode, Table 3). There are no reports about bovine CFG size available. In a comprehensive review, Martini et al. (2016) suggested that characteristics of MFG affect milk quality and digestive parameters, although available data regarding the effects of the MFG diameter on digestibility are conflicting. Our results suggested that smaller CFG diameter at the first postpartum milking can enable efficient fat and energy assimilation for calves. It can also relate to the unique ability of neonatal enterocytes to absorb protein macromolecules (Sangild, 2003). As colostrum fat content decreases over time (Elfstrand et al., 2002), the increase of CFG size does not support previous reports that state posi- tive relationships between daily fat secretion and average MFG diameter (Wiking et al., 2004; Carroll et al., 2006). However, Argov et al. (2008) hypothesized that as the membrane of the mammary epithelial cell is lost to envelop the globule, larger MFG may be secreted to reduce membrane loss. This might also be one of the explanations for the CFG size increase reported in this study. For ewes, the CFG in milk has been found to be larger immediately postpartum $(10 \mathrm{~h})$ than in subsequent days (Martini et al., 2012), and a similar tendency has been reported for human colostrum (Michalski et al., 2005). The MFG mean diameter of cow milk has been found to decrease slightly during lactation, being close to $5.5 \mu \mathrm{m}$ at the start of lactation $(5-30 \mathrm{~d})$ and ending up around $4.5 \mu \mathrm{m}$ at $>305 \mathrm{~d}$ (Fleming et al., 2017). These results, together with our measurements, suggest that the MFG mean diameter peaks shortly after postpartum (up to $40 \mathrm{~h}$ ) and decreases relatively rapidly after this peak. Further studies are required to verify the rapid decrease of fat globule size in transition milk (2-5 d postpartum).

Parity. Lactation number had a significant effect on volume moment mean $(\mathrm{D}[4,3], P=0.034)$ and larger fat globules (Dv 90, $P=0.011$ ). It had a nonsignificant influence on median CFG size (Dv50, $P=0.194$ ), smaller fat globules (Dv10, $P=0.06)$, and mode $(P$ $=0.499 ;$ Table 3 ). However, mode was the only CFG size variable that demonstrated a significant milking by lactation interaction effect $(P=0.015)$. Previous findings about the lactation effects on cow MFG size are mixed; Walter et al. (2019) reported smaller MFG size on first- and second-parity cows (140 individual cows from 1 herd), whereas Fleming et al. (2017) showed no significant effect of parity (399 individual cows from 44 herds). Walter et al. (2019) suggested the effect of parity was relatively small compared with the between-herd and between-breed variations in the study by Fleming et al. (2017), whereas following the same herd allowed capturing the independent effect of parity. Overall, it seems that lactation has little effect on CFG size.

\section{Fatty Acid Profile}

Altogether, 10 SFA, 4 MUFA, and 3 PUFA were identified from the colostrum samples used in this study, with SFA accounting for $64.9 \%$, MUFA for $31.4 \%$, and PUFA for $3.7 \%$ of the FA profile. Palmitic acid (C16:0), oleic acid (C18:1 cis-9), and linoleic acid (C18:2n-6) were the main SFA, MUFA, and PUFA, respectively (Figure 2; Table 4). These results are in line with FA profiles reported in earlier studies (Laakso et al., 1996; Contarini et al., 2014; O'Callaghan et al., 2020).

Postpartum Milking. In general, short-chain (C410) SFA concentrations increased with the number of 


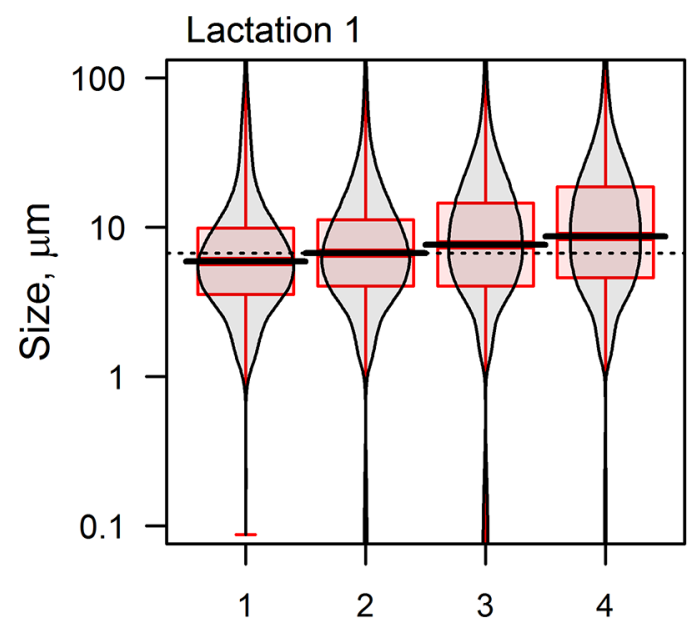

Lactation 2

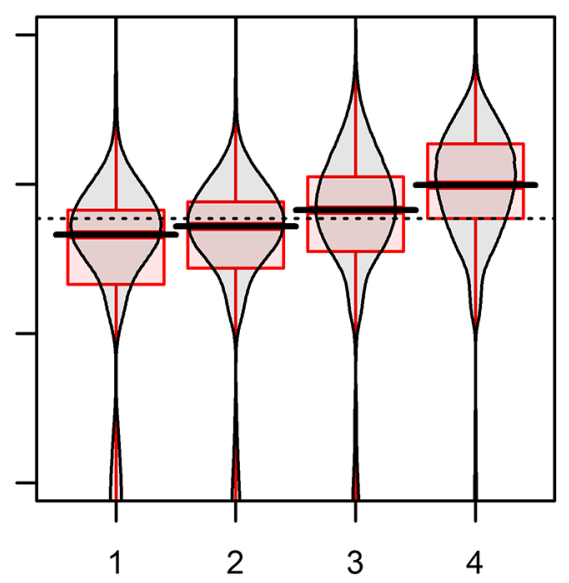

Lactation 3-7

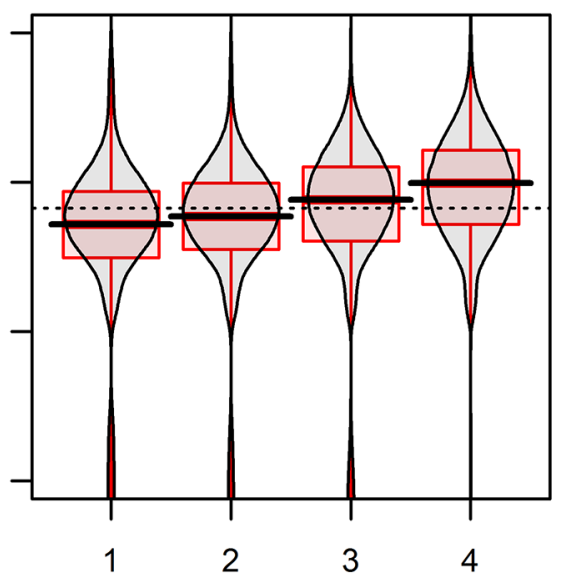

$(\mathrm{A})$

\section{Milking}

$\rightarrow$ Lactation 1 -O- Lactation 2 -.o- Lactation 3-7
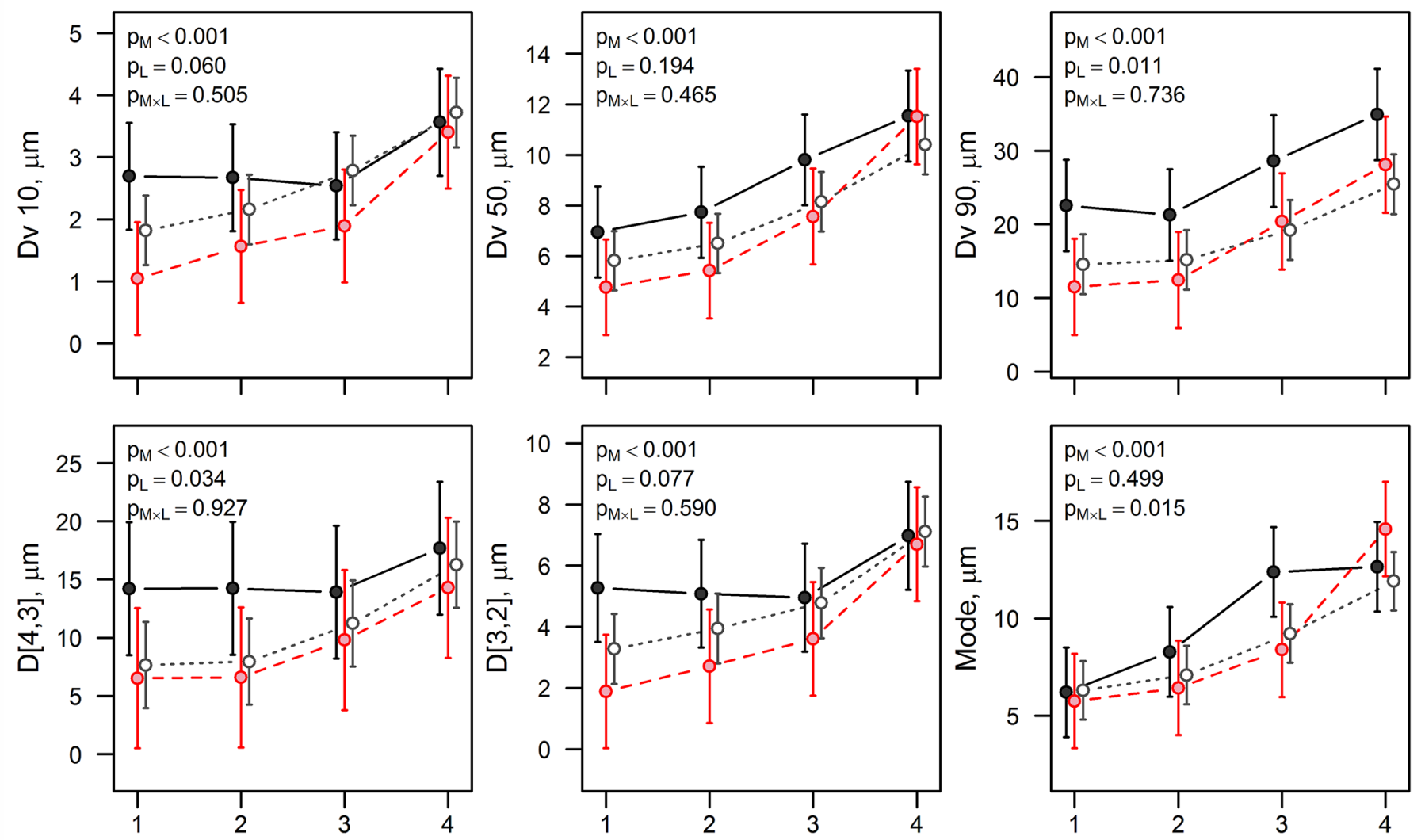

(B)
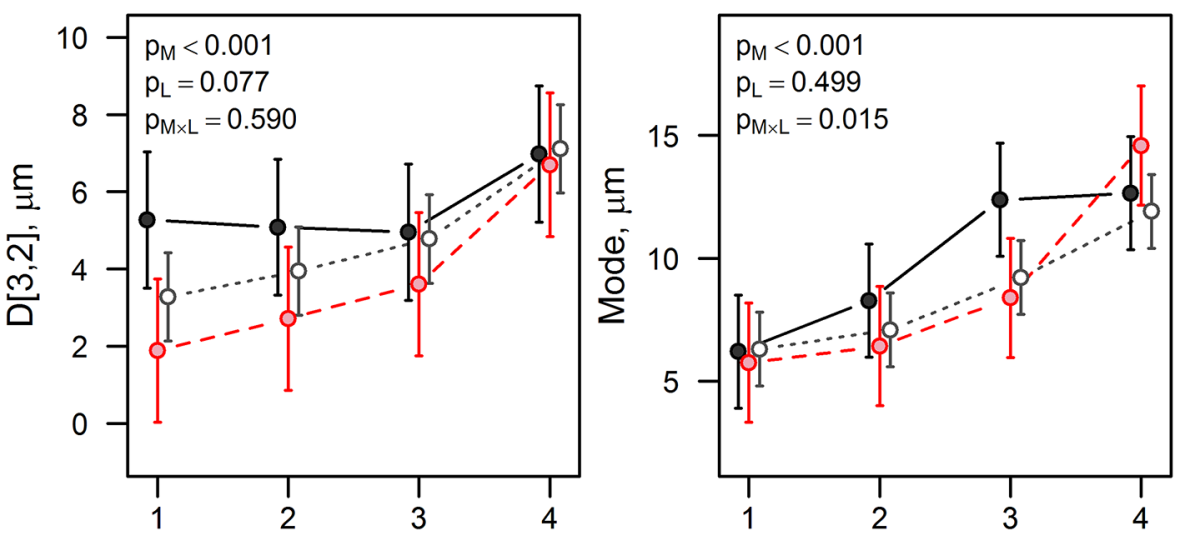

Figure 1. (A) Bovine colostrum fat globule size distribution at the first 4 postpartum milkings depending on lactation number (first lactation, $\mathrm{n}=40$; second lactation, $\mathrm{n}=36$; third and later lactations, $\mathrm{n}=111$ ). Each distribution shows the mean globule size distribution and globule size axes are presented on a $\log _{10}$ scale; red boxes denote the area of the middle $50 \%$ of globule sizes, strong black lines mark the median globule size by milkings, and dotted lines indicate the median globule size over 4 milkings. (B) Model-based means (with 95\% CI) of bovine colostrum fat globule size first decile (Dv 10), median (Dv 50), last decile (Dv 90), D[4,3], D [3,2], and mode depending on milking and lactation. Significance of milking $\left(\mathrm{p}_{\mathrm{M}}\right)$, lactation $\left(\mathrm{p}_{\mathrm{L}}\right)$ and milking by lactation interaction $\left(\mathrm{p}_{\mathrm{M}} \times \mathrm{L}\right)$ effects are presented. 


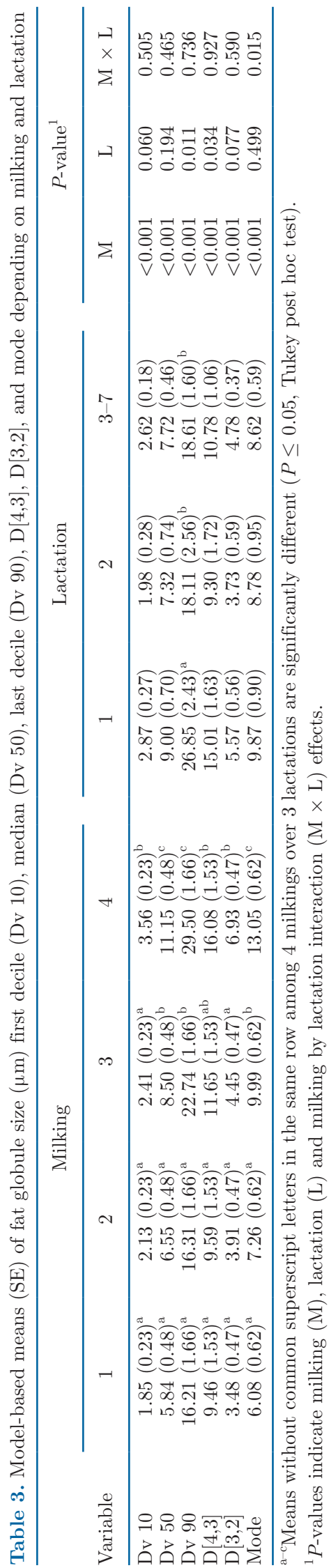

postpartum milkings (Figure 3), whereas medium-chain (C11-15) and long-chain (C16-20) SFA decreased (except for second lactation C12:0). These results are in line with the dynamics of FA profile in colostrum and transition milk described by Contarini et al. (2014) and in a comprehensive study by O'Callaghan et al. (2020). It is also in agreement with the well-described positive association between MFG size (greater triglyceride to membrane ratio) and shorter-chain FA contents (Couvreur and Hurtaud, 2017). There are some discrepancies between the findings of this study and the findings of O'Callaghan et al. (2020) in long-chain FA (C18:0, C20:0) that can be explained by differences in housing and feeding conditions. Indeed, approximately half of long-chain FA $(\geq \mathrm{C} 18)$ are derived from the diet, whereas the majority of smaller (C4:0-C14:0) FA originate from de novo FA synthesis in the mammary gland (Palmquist, 2006).

Among medium-chain MUFA, only C14:1 cis-5 increased with milking number, with an exception for the second-lactation samples where it decreased. Longchain MUFA also increased (except for second lactation C20:1 cis-9), whereas PUFA decreased. Overall, SFA and PUFA decreased, and MUFA increased. Similar dynamics in SFA, MUFA, and PUFA have been reported previously (Contarini et al., 2014; O'Callaghan et al. 2020), with Contarini et al. (2014) reporting distinctive profiles in the longer term $(72,96$, and 120 $\mathrm{h}$ postpartum) and not in the short term (24 and $48 \mathrm{~h}$ postpartum). The fact that PUFA are mainly associated with the MFG membrane (Couvreur and Hurtaud, 2017), and that the content of the latter decreases when MFG size increases, may provide an explanation for the phenomenon of reduced PUFA over time. The atherogenic index decreased, and DI (except for second lactation DI14) increased with postpartum milking number in this study. The decreasing atherogenic index suggests that, in terms of cholesterol content (Poppitt et al., 2002) and food production (Bobe et al., 2003), transition milk can outperform colostrum.

Differences in FA content are most evident at the fourth milking (Figure 2; Table 4). This supports the common understanding that colostrum production lasts around $24 \mathrm{~h}$ postpartum and that the fourth milking (36-40 h postpartum) should be considered transition milk. This knowledge is useful when considering nutritional and feeding aspects while developing colostrum and transition milk valorization technologies.

Parity. The short-chain SFA and C20:2n-6 decreased with increasing lactation number (Figure 2). Mediumchain and long-chain SFA, however, did not show clear change with increasing lactation number, as the second-lactation samples had the highest concentrations of $\mathrm{C} 12: 0$ and $\mathrm{C} 14: 0$, and lowest of $\mathrm{C} 15: 0, \mathrm{C} 16: 0$ and 

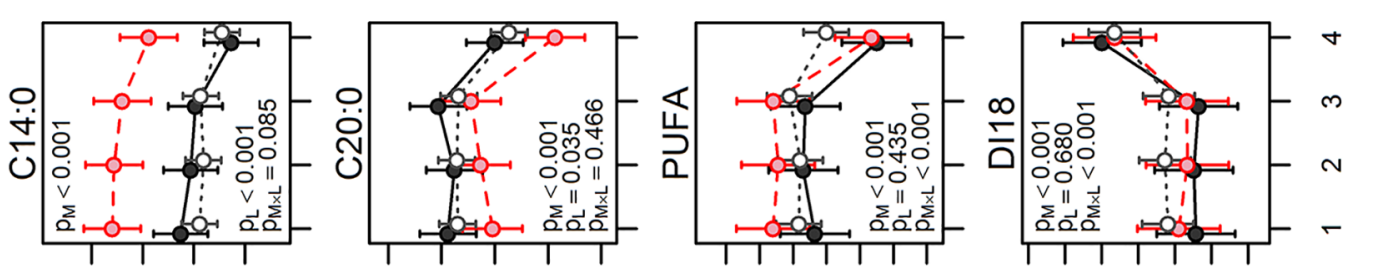

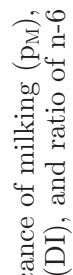

tr Ol 8

sE.0 GZ: s.०

乙'† $\quad 8^{\circ} \varepsilon \quad \dagger^{\circ} \varepsilon \quad 0^{\circ} \varepsilon$

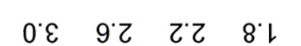
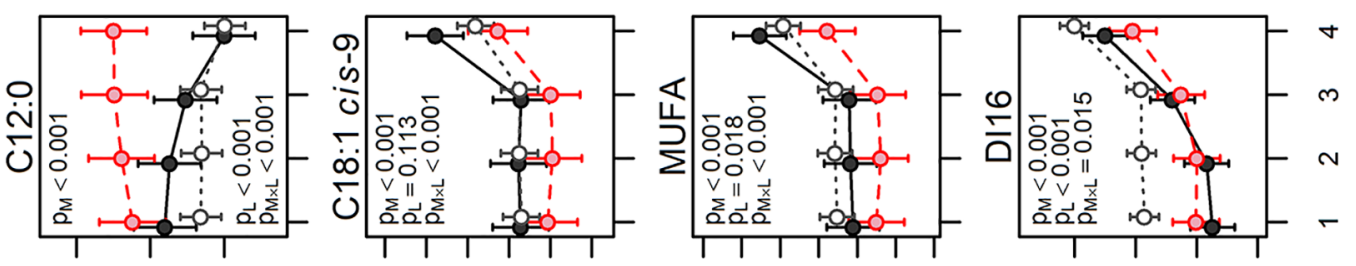

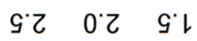

乙E $8 乙 \quad \nabla 乙$

$8 \varepsilon \quad \nabla \varepsilon \quad 0 \varepsilon \quad 92$
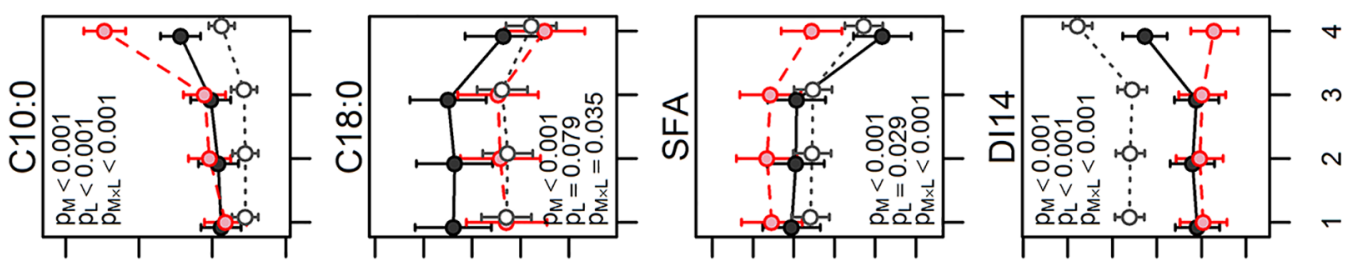

$\begin{array}{lllllll}0 . & \text { G.l } & 0.1 & \text { G.0 } & \text { sl } & \varepsilon L & l l\end{array}$

$89 \quad 79 \quad 09$
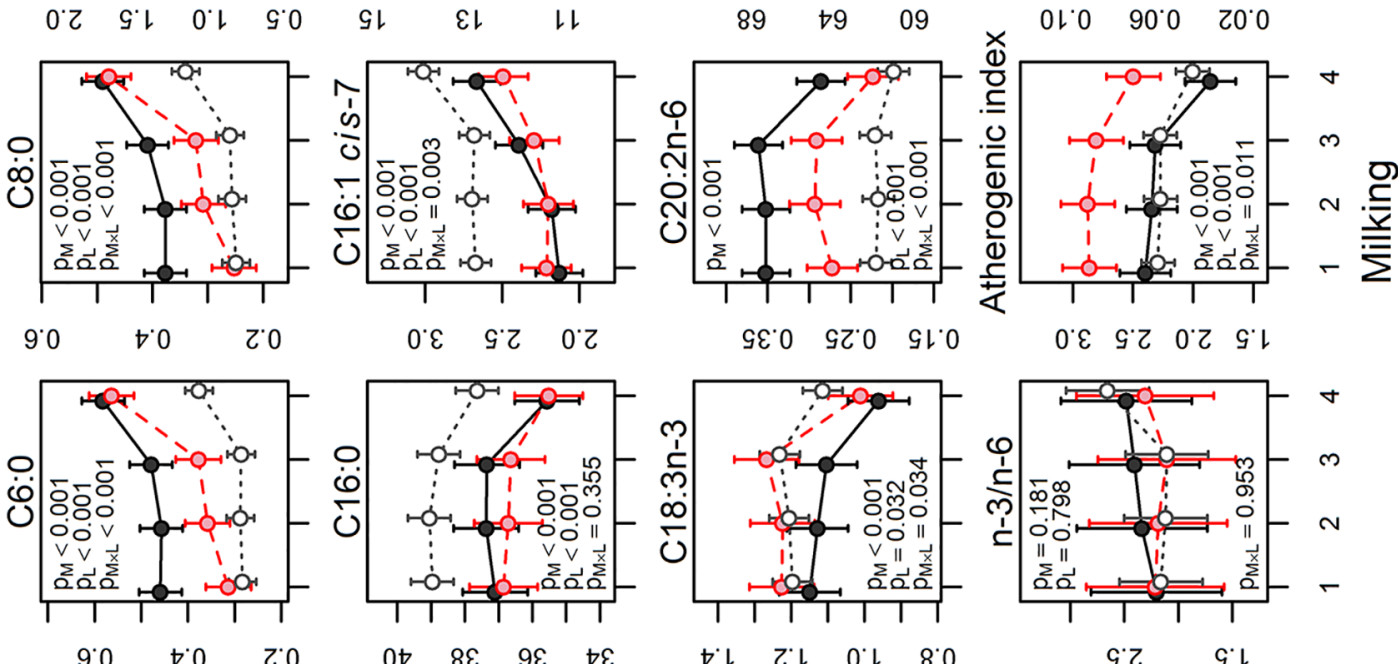

$\begin{array}{lll}0 & \varepsilon & S^{\prime} Z \quad 0^{\circ} Z\end{array}$
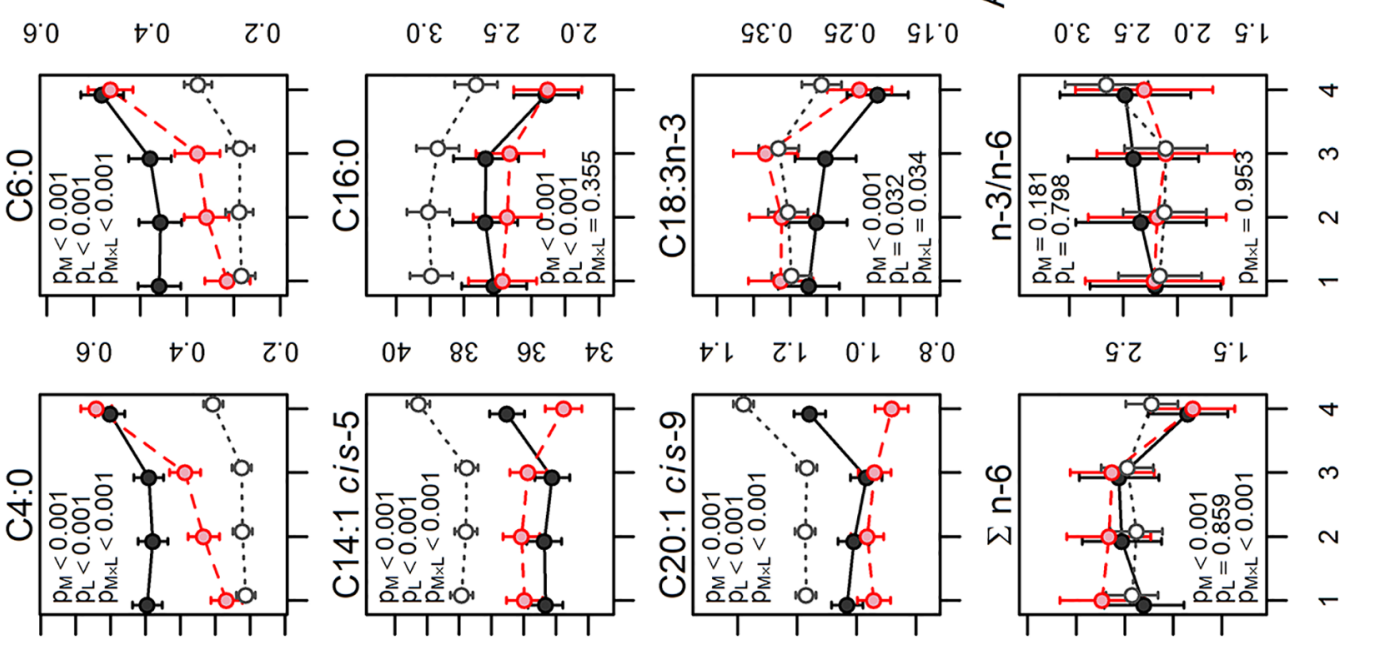

เレ で $0.1 \quad 8.0$
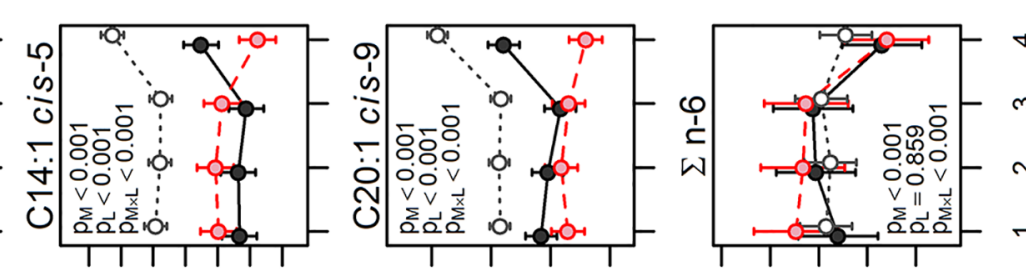

$\begin{array}{llll}L^{\prime} 0 & G^{\prime} 0 & \varepsilon^{\prime} 0 & l^{\prime} 0\end{array}$
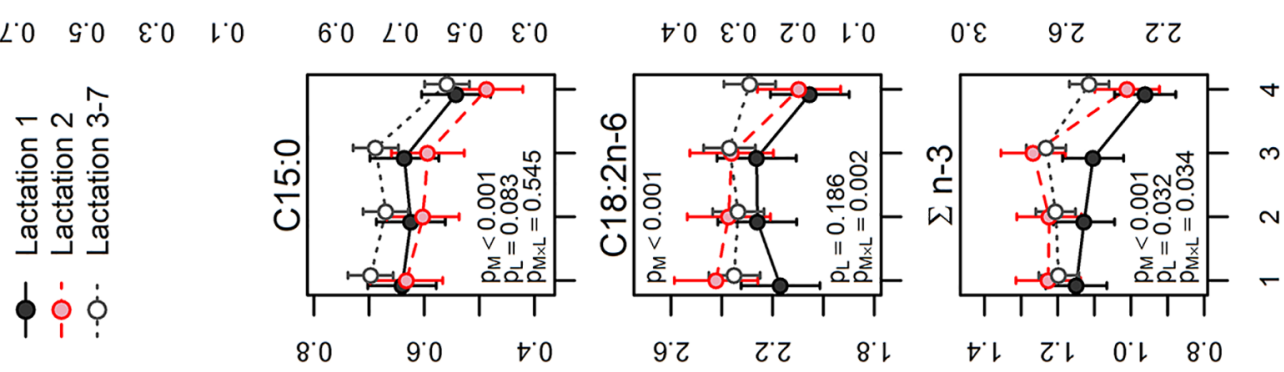

เレ Z゙ 0.180 


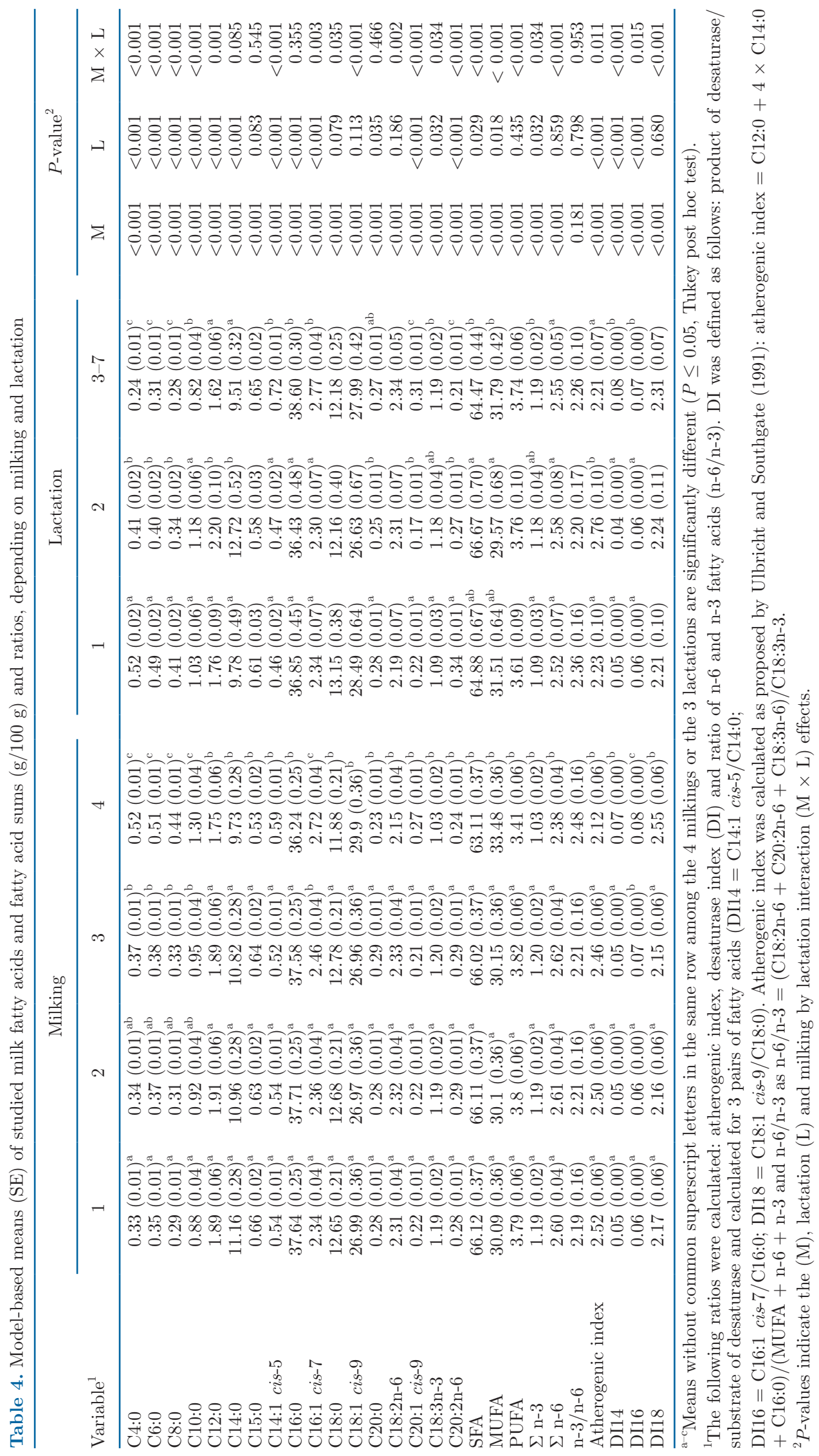



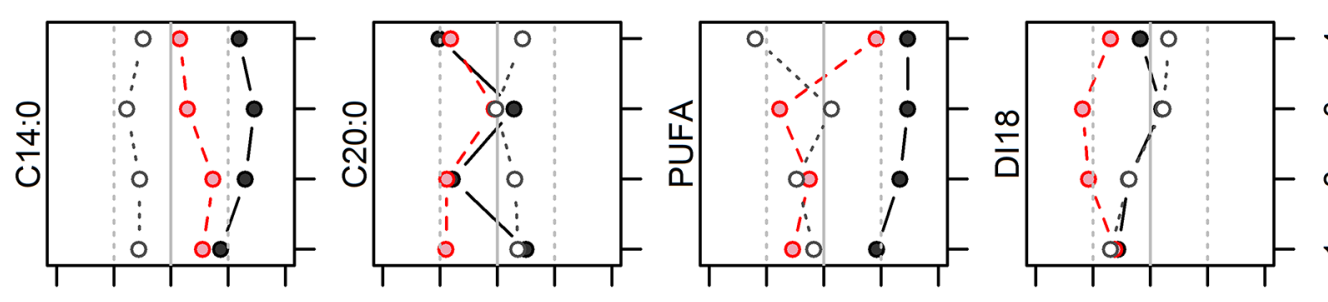

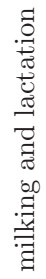
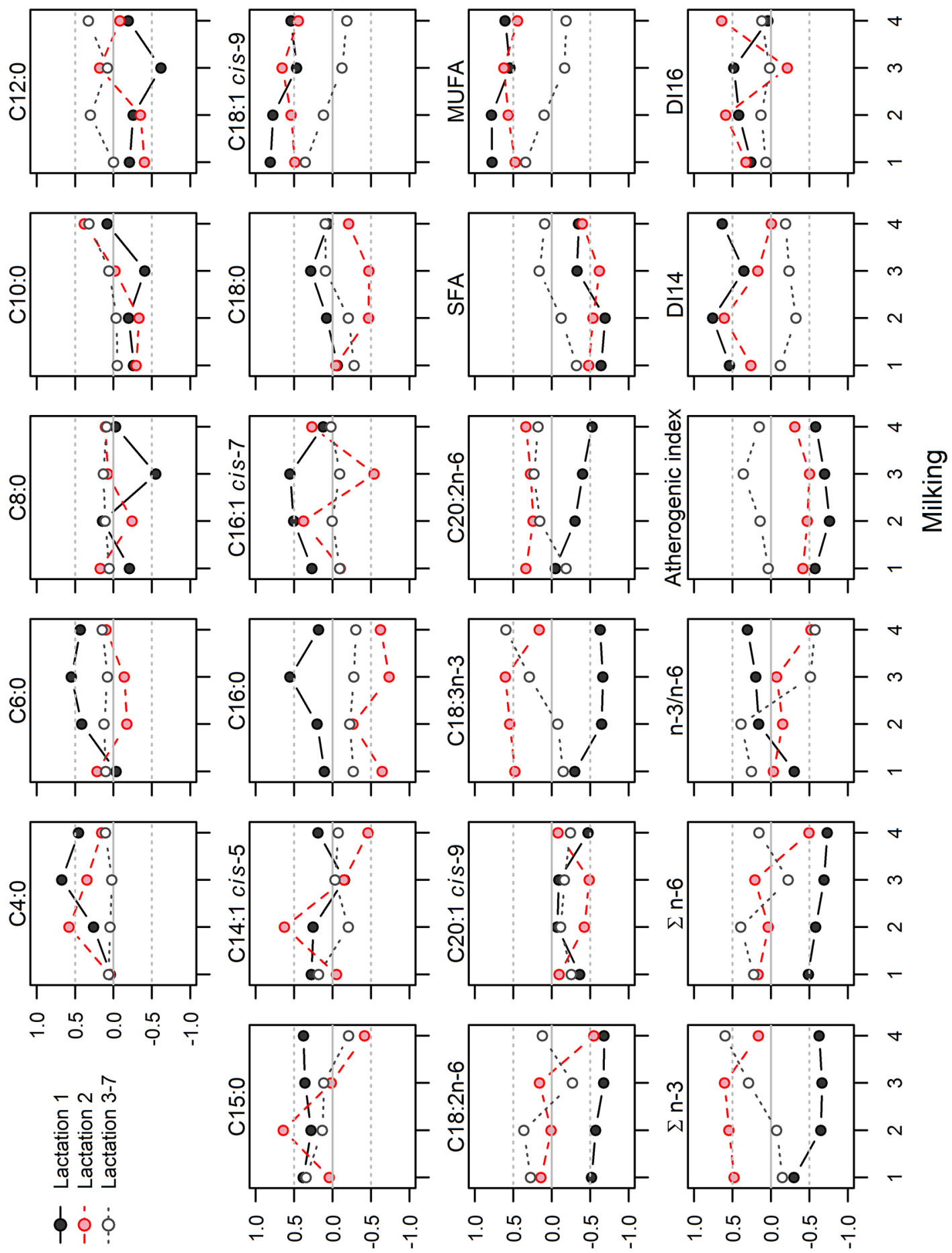

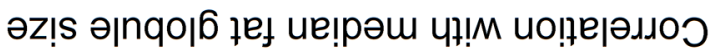


C20:0. Lactation number had a significant $(P=0.029)$ effect on overall SFA, with samples from cows in their second lactation having the highest values, especially at the fourth milking. The short-chain SFA content of the first milking of second-lactation samples was similar to lactation numbers 3 to 7 , whereas the fourth milking resembled the first lactation. Thus, it seemed that although the colostrum of cows in the second lactation initially had similar quality to colostrum from cows in their third milking, this quality was not as persistent for cows that were in their third or later lactation. In the case of $\mathrm{C} 14: 1 \mathrm{n}-5$ to $\mathrm{C} 14: 1$ cis-5, C16:1n-7 to C16:1 cis-7, and C20:1n-9 to C20:1 cis-9, colostrum from cows in their third to seventh lactations had the highest values. The same trend was evident for MUFA in the first to third milkings.

Our findings are in agreement with earlier studies showing that parity has the strongest effect on shortchain, de novo FA (Mele et al., 2016). The difference in colostrum short-chain SFA profile is also evident when primiparous and multiparous colostrum samples are compared and lactation numbers are not distinguished, presumably reflecting individual responses of cows to increased energy requirements at the onset of lactation (Contarini et al., 2014). O'Callaghan et al. (2020) reported nonsignificant effects of parity on colostrum short-chain SFA, which might stem from their small sample size (6 cows per lactation) and longer sampling period $(0-5 \mathrm{~d})$. However, O'Callaghan et al. (2020) also demonstrated that parity had a significant effect on some medium and long-chain FA (C14:1, C15:0, C16:0, C18:0, C18:2n-6, C18:3n-3, C20:0, CLA, and $\mathrm{C} 21: 0)$, most of which are in agreement with our findings.

For short-chain SFA content, second-lactation cows had similar values to the third- to seventh-lactation cows during the first milking, but increased with milking number, reaching a similar level as the first lactation cows by the fourth milking. As the majority of short-chain FA originate from de novo FA synthesis (Palmquist, 2006), this pattern can reflect the development and condition of the mammary gland. Highest atherogenic index values are in samples from the second lactation; therefore, from a consumer (Poppitt et al., 2002) and food production aspect (Bobe et al., 2003), second-lactation cow colostrum is least desirable.

\section{Correlations Between Fat Globule Size and FA Content}

CFG Size Median and FA. The correlations between short-chain SFA content and CFG median size (Figure 3 ) indicated that samples from primiparous cows with larger CFG tended to have higher contents of C4:0 and C6:0 in the second, third, and fourth milkings, whereas no such positive correlation was found in samples collected from cows in the second to seventh lactations. Among medium-chain SFA, the clearest pattern was evident for C16:0 and C14:0. The samples from multiparous cows had a negative correlation between CFG size and C16:0 content, whereas samples from primiparous cows showed a negative correlation with C14:0. In first- and second-lactation cows, the CFG size was negatively correlated with overall SFA, and positively correlated with MUFA and DI14. In primiparous cows, the CFG size was negatively correlated with PUFA and omega FA contents, whereas these correlations in multiparous cows were positive.

The correlations reported in this study agree with those reported by Lopez et al. (2011). However, here we also demonstrated the effect of parity, which was not addressed by Lopez et al. (2011). The negative correlation between CFG size and C14:0 was most likely driving the positive correlations between CFG size and DI14 value. The correlations between DI14, DI16, and DI18 and CFG size were not similar to each other (Figure 3). The most probable explanation for this is the different origin of these $\mathrm{FA} ;<\mathrm{C} 14 \mathrm{FA}$ originate from de novo FA synthesis, $\geq \mathrm{C} 18 \mathrm{FA}$ are derived from the diet, and $\mathrm{C} 16$ are derived from both (Palmquist, 2006). Interestingly, in the samples from the primiparous cows, the correlations (Figure 3 ) of the well-known relationships discussed above (larger MFG, more shortchain FA; smaller MFG, less MFG membrane, fewer long-chain FA) were more evident than in the samples from multiparous cows. The colostrum of primiparous cows has lower quality than that of multiparous cows (Dunn et al., 2017). Thus, our results might suggest that primiparous and multiparous cows differ not only regarding their colostrum and milk composition, but also in their metabolism and milk syntheses mechanisms. The mechanisms behind these differences, which can lie for example in the metabolism, development, or condition of the mammary gland, need to be addressed in future studies.

Higher values of DI and MUFA, accompanied by a decrease in SFA, have been connected to the prevention of the risks of cardiovascular diseases (Reh et al., 2004), making the colostrum of first- and second-lactation cows especially desirable. Considering the atherogenic index, the colostrum with bigger fat globules, originating from cows in the first and second lactations (Figure 3 ), is highly valuable as a product with a lower atherogenic index can decrease both total and low-density lipoprotein cholesterol (Poppitt et al., 2002). In addition, butter produced from milk with lower atherogenic 

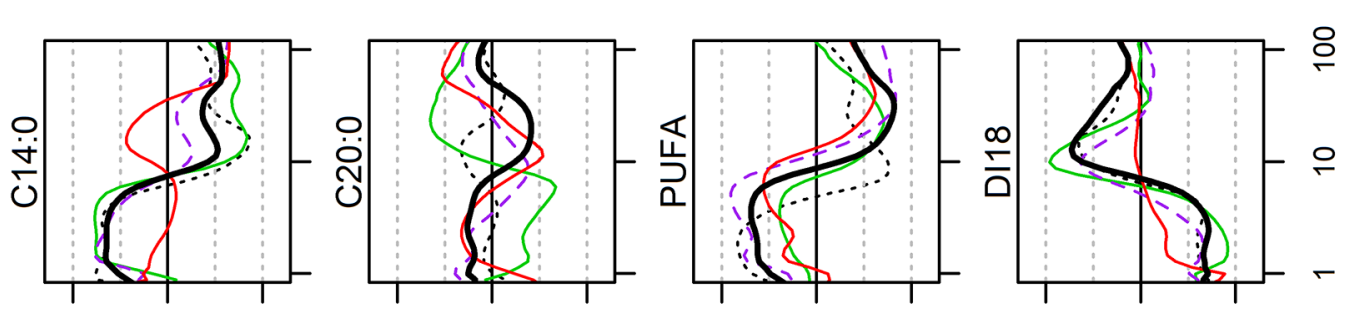

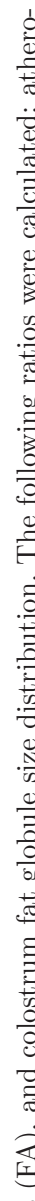
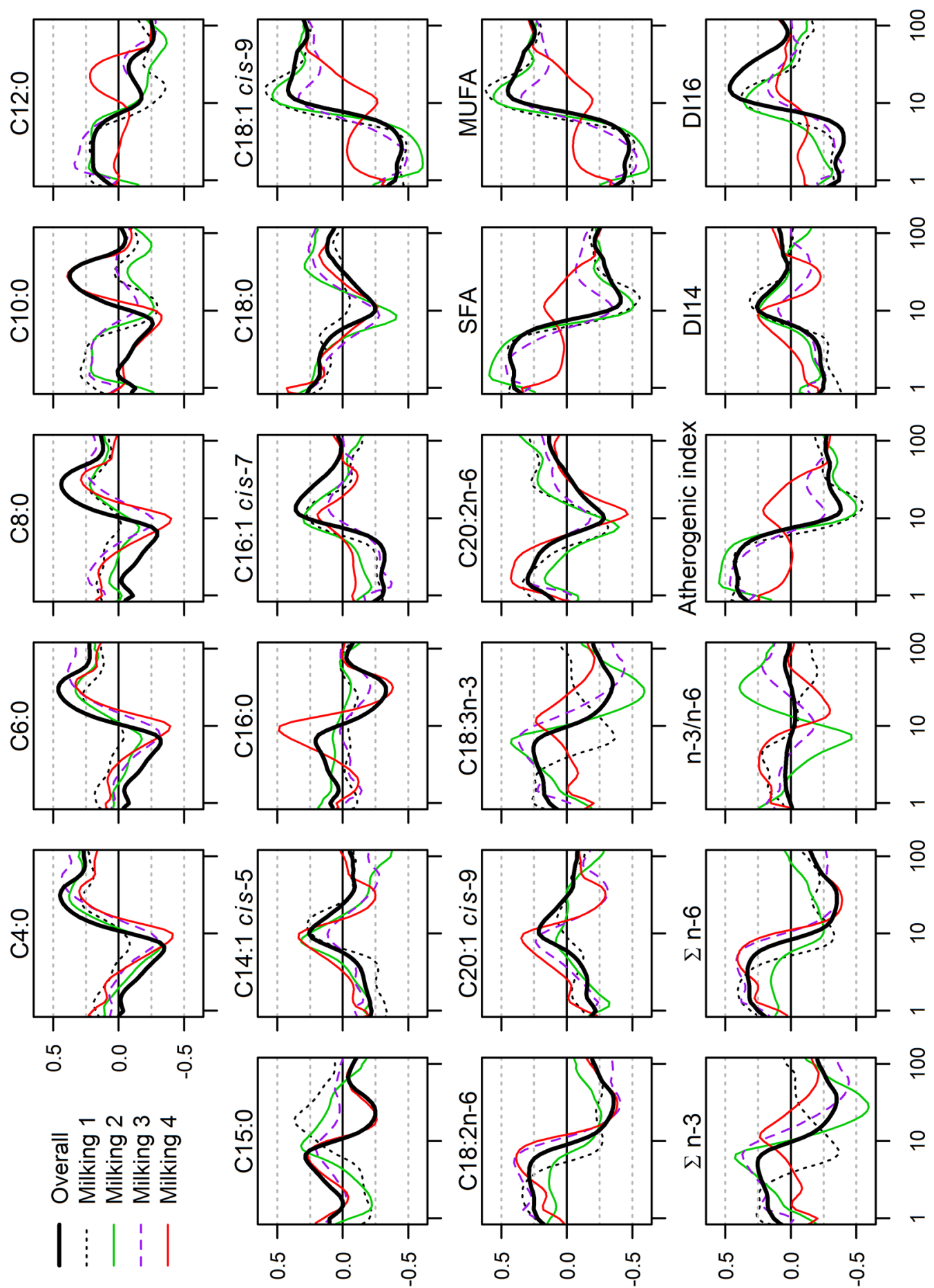

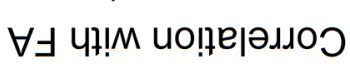
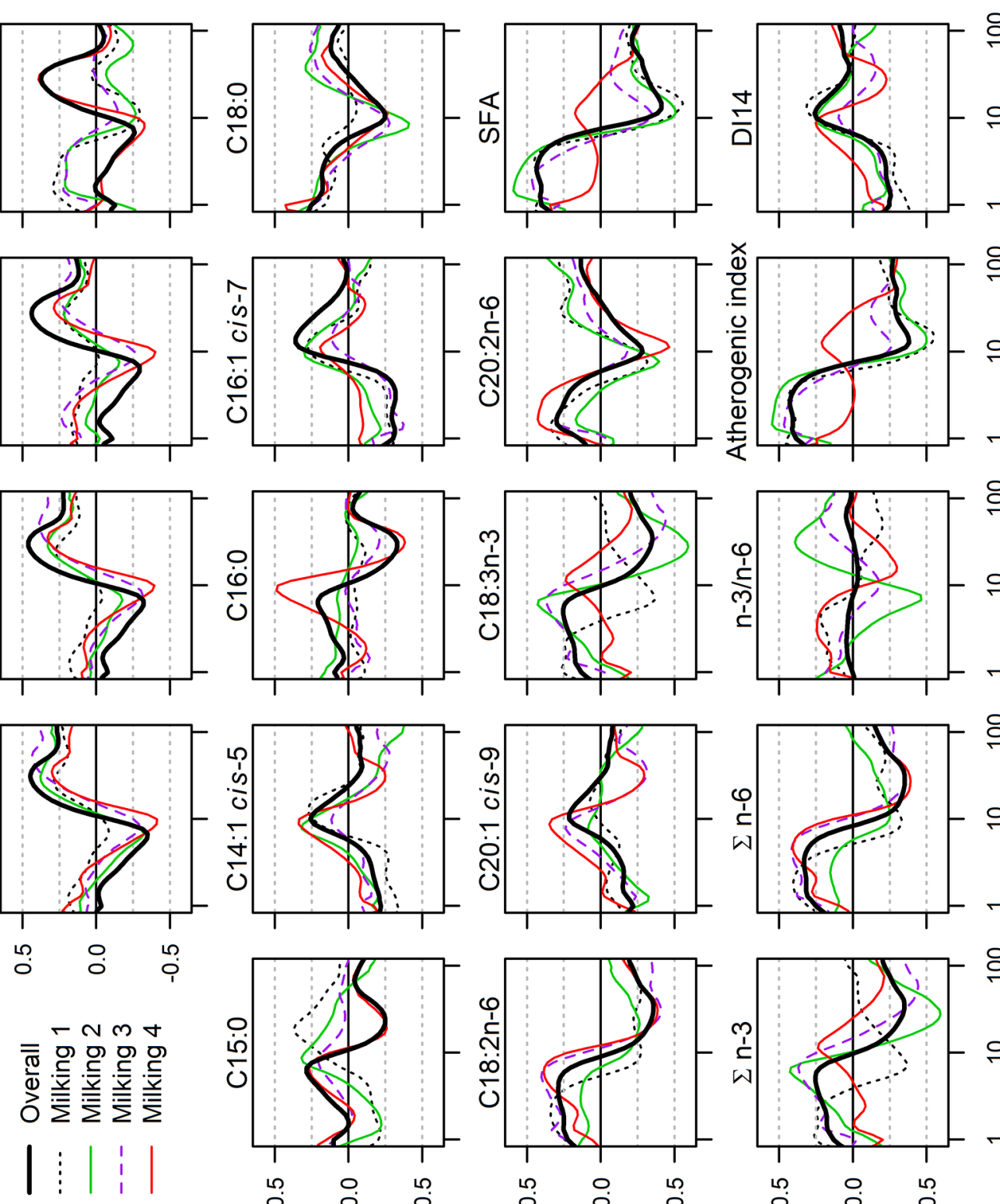


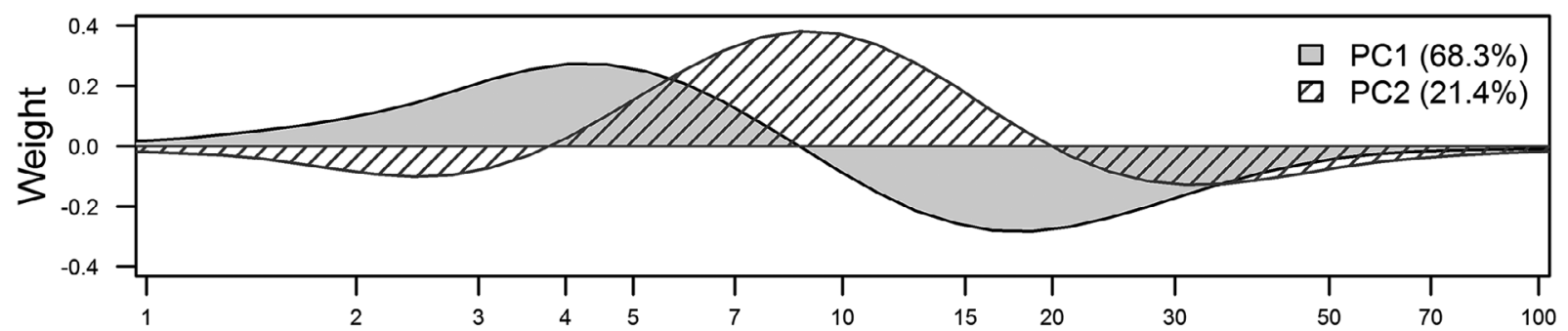

(A)

Size, $\mu \mathrm{m}$

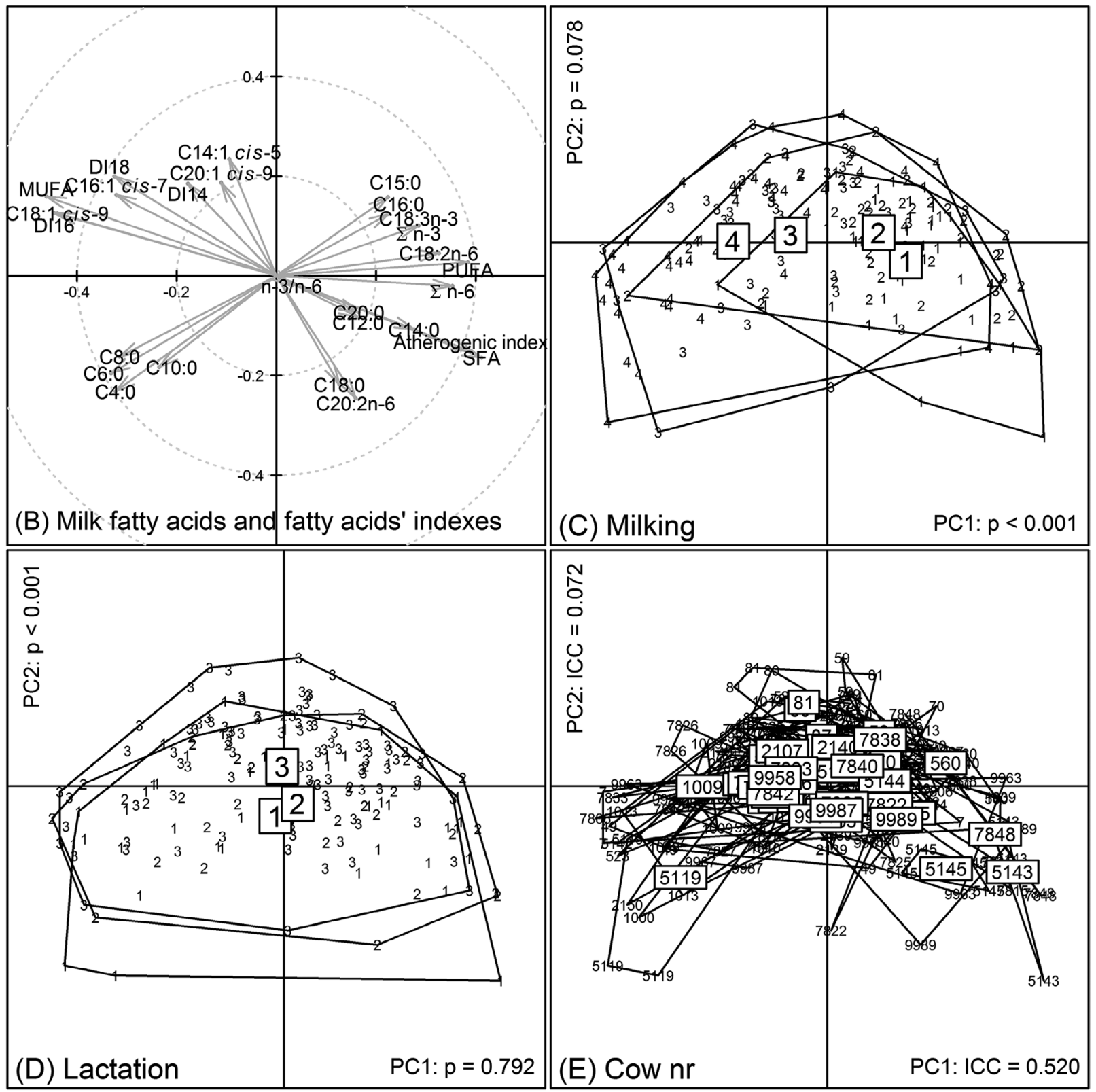

Figure 5. Results of principal component (PC) analysis of bovine colostrum fat globule size distributions in the interval 1 to $100 \mu \mathrm{m}$. (A) The weights (eigenvectors) of different fat globule size subintervals' frequencies in the first 2 principal components. (B) Correlations of the first 2 PC scores with milk fatty acids and fatty acid indices. (C-E) Location of samples according to their first 2 PC scores sorted by milking, lactation number, and cow. Each sample is marked with its group symbol, and samples from the same group are surrounded by a line; higher values in boxes mark the groups' centroids and $P$-values denote the significance of the factors according to the linear mixed model, considering fixed effects of milking and lactation number as well as random effect of cow. For the random cow effect, the proportion of variance of PC scores considered by the cow effect (intraclass correlation coefficient) is presented; for both PC, separate models were fitted. 
index is more spreadable and less adhesive (Bobe et al., 2003).

CFG Size Distribution and FA. The strengths and directions of correlations between FA and CFG size fluctuated between positive and negative values (Figure 4). This suggested that the FA concentration was dependent on the size of the CFG (or vice versa). In general, the first to third milkings showed similar correlations to each other, whereas milk from the fourth milking was clearly different for SFA, MUFA, and atherogenic index. This provided further support to our previous suggestion that the fourth milking should be considered transition milk. The associations between the CFG size and FA also have practical value as this information enables the modification of the FA profile of colostrum products by manipulating the size distribution. For example, colostrum with bigger fat globules should be preferred to achieve lower atherogenic index value and SFA content.

Principal Component Analysis. The PCA analyses indicated that most of the variation in CFG size distribution [the first principal component (PC1) explained $68.3 \%$ of the variation] was caused by the contrast between particle size frequencies below and above $10 \mu \mathrm{m}$. (Figure 5A). The PC1 considered mainly the differences between postpartum milkings (Figure $5 \mathrm{C})$; at the first milkings, the frequency of smaller (10 $\mu \mathrm{m})$ globules was higher. The random cow effect explained $53.9 \%$ of the variability of $\mathrm{PC} 1$, indicating that the particle size ranges related to $\mathrm{PC} 1$ were strongly animal-specific (Figure 5E). The PCA addressing the correlations between all measured FA simultaneously had stronger positive relationships (higher FA concentration, smaller CFG) with atherogenic index, medium- and long-chain SFA, omega FA, and PUFA, and negative relationships (higher FA concentration, larger CFG) with DI16, DI18, short-chain SFA, and MUFA (Figure 5B). These relationships are in line with the correlations between individual FA and CFG size discussed above and with well-established associations between MFG size, FA chain length, and MFG membrane (Couvreur and Hurtaud, 2017). These relationships are in agreement with the results of the correlations between individual FA and CFG size discussed above. The second PCA (explaining 21.1\% of the globule size variability) contrasted the frequency of particles with sizes around $10 \mu \mathrm{m}$ and $<4$ or $>20 \mu \mathrm{m}$ (Figure 5A). It distinguished the samples according to lactation (Figure $5 \mathrm{C}$ ); the samples from higher lactation numbers had a slightly higher frequency of fat globules of a size around $10 \mu \mathrm{m}$. This finding is in agreement with Walter et al. (2019), who reported smaller MFG size in first- and second-parity cows. However, no significant effect of parity has also been reported (Fleming et al., 2017), indicating that the lactation effect on MFG size is not yet fully clear.

\section{CONCLUSIONS}

This study provided the first evidence about bovine colostrum CFG size distribution. We showed that the CFG size almost doubled during the first 4 postpartum milkings, whereas lactation number had little effect on CFG size. The FA profile was similar in the first 3 milkings and became distinctive in the fourth milking. Correlation analyses between CFG size and FA showed medium strength relationships, and these also indicated that the fourth milking differed from previous milkings. Our results suggested that up to the third postpartum milking, milk can be considered colostrum; however, at the fourth milking, the milk should be considered transition milk. This knowledge enables more efficient and targeted production of colostrum-based foods and food supplements. Furthermore, our study suggested that size-based segregation of CFG allows for the modification of colostrum products FA profile.

\section{ACKNOWLEDGMENTS}

We are grateful to D. Arney (Estonian University of Life Sciences, Tartu) and K. Koorem (University of Tartu, Tartu) for comments on earlier versions of the manuscript. The publication of this work was supported by the European Union's Horizon 2020 research and innovation programme under grant agreement No. 810630 "ERA Chair for Food (By-) Products Valorization Technologies of the Estonian University of Life Sciences (VALORTECH)" and the Estonian University of Life Sciences research and development base financing (P170195VLTQ). The authors have not stated any conflicts of interest.

\section{REFERENCES}

Argov, N., D. G. Lemay, and B. German. 2008. Milk fat globule structure and function: Nanoscience comes to milk production. Trends Food Sci. Technol. 19:617-623. https://doi.org/10.1016/j.tifs.2008 .07 .006 .

Baum, S. J., P. M. Kris-Etherton, W. C. Willett, A. H. Lichtenstein, L. L. Rudel, K. C. Maki, J. Whelan, C. E. Ramsden, and R. C. Block. 2012. Fatty acids in cardiovascular health and disease: A comprehensive update. J. Clin. Lipidol. 6:216-234. https://doi .org/10.1016/j.jacl.2012.04.077.

Bobe, G., E. Hammond, A. Freeman, G. Lindberg, and D. Beitz. 2003. Texture of butter from cows with different milk fatty acid compositions. J. Dairy Sci. 86:3122-3127. https://doi.org/10.3168/jds .S0022-0302(03)73913-7. 
Carroll, S. M., E. J. DePeters, S. J. Taylor, M. Rosenberg, H. PerezMonti, and V. A. Capps. 2006. Milk composition of Holstein, Jersey, and Brown Swiss cows in response to increasing levels of dietary fat. Anim. Feed Sci. Technol. 131:451-473. https://doi.org/ 10.1016/j.anifeedsci.2006.06.019.

Contarini, G., M. Povolo, V. Pelizzola, L. Monti, A. Bruni, L. Passolungo, F. Abeni, and L. Degano. 2014. Bovine colostrum: Changes in lipid constituents in the first 5 days after parturition. J. Dairy Sci. 97:5065-5072. https://doi.org/10.3168/jds.2013-7517.

Couvreur, S., and C. Hurtaud. 2017. Relationships between milks differentiated on native milk fat globule characteristics and fat, protein and calcium compositions. Animal 11:507-518. https://doi .org/10.1017/S1751731116001646.

Dunn, A., A. Ashfield, B. Earley, M. Welsh, A. Gordon, and S. J. Morrison. 2017. Evaluation of factors associated with immunoglobulin $\mathrm{G}$, fat, protein, and lactose concentrations in bovine colostrum and colostrum management practices in grassland-based dairy systems in Northern Ireland. J. Dairy Sci. 100:2068-2079. https://doi.org/ $10.3168 /$ jds.2016-11724.

Duplessis, M., S. Mann, D. V. Nydam, C. L. Girard, D. Pellerin, and T. R. Overton. 2015. Folates and vitamin B12 in colostrum and milk from dairy cows fed different energy levels during the dry period. J. Dairy Sci. 98:5454-5459. https://doi.org/10.3168/jds .2015-9507.

Edén, J., P. Dejmek, R. Löfgren, M. Paulsson, and M. Glantz. 2016. Native milk fat globule size and its influence on whipping properties. Int. Dairy J. 61:176-181. https://doi.org/10.1016/j.idairyj 2016.06.004

Elfstrand, L., H. Lindmark-Mansson, M. Paulsson, L. Nyberg, and B. Akesson. 2002. Immunoglobulins, growth factors and growth hormone in bovine colostrum and the effects of processing. Int. Dairy J. 12:879-887. https://doi.org/10.1016/S0958-6946(02)00089-4

Fleming, A., F. S. Schenkel, J. Chen, F. Malchiodi, R. A. Ali, B. Mallard, M. Sargolzaei, M. Corredig, and F. Miglior. 2017. Variation in fat globule size in bovine milk and its prediction using mid-infrared spectroscopy. J. Dairy Sci. 100:1640-1649. https://doi.org/ 10.3168/jds.2016-11427.

Garcia, C., C. Antona, B. Robert, C. Lopez, and M. Armand. 2014. The size and interfacial composition of milk fat globules are key factors controlling triglycerides bioavailability in simulated human gastro-duodenal digestion. Food Hydrocoll. 35:494-504. https:// doi.org/10.1016/j.foodhyd.2013.07.005.

Jaakamo, M. J., T. J. Luukkonen, P. K. Kairenius, A. R. Bayat, S. A. Ahvenjärvi, T. M. Tupasela, J. H. Vilkki, K. J. Shingfield, and H. M. Leskinen. 2019. The effect of dietary forage to concentrate ratio and forage type on milk fatty acid composition and milk fat globule size of lactating cows. J. Dairy Sci. 102:8825-8838. https:/ /doi.org/10.3168/jds.2018-15833.

Kehoe, S. I., B. M. Jayarao, and A. J. Heinrichs. 2007. A survey of bovine colostrum composition and colostrum management practices on Pennsylvania dairy farms. J. Dairy Sci. 90:4108-4116. https:// doi.org/10.3168/jds.2007-0040.

Laakso, P., P. Manninen, J. Mäkinen, and H. Kallio. 1996. Postparturition changes in the triacylglycerols of cow colostrum. Lipids 31:937-943. https://doi.org/10.1007/BF02522686.

Logan, A., M. Auldist, J. Greenwood, and L. Day. 2014. Natural variation of bovine milk fat globule size within a herd. J. Dairy Sci. 97:4072-4082. https://doi.org/10.3168/jds.2014-8010.

Lopez, C., V. Briard-Bion, O. Ménard, E. Beaucher, F. Rousseau, J. Fauquant, N. Leconte, and B. Robert. 2011. Fat globules selected from whole milk according to their size: Different compositions and structure of the biomembrane, revealing sphingomyelin-rich domains. Food Chem. 125:355-368. https://doi.org/10.1016/j .foodchem.2010.09.005.

Martini, M., I. Altomonte, and F. Salari. 2012. The lipid component of Massese ewes' colostrum: Morphometric characteristics of milk fat globules and fatty acid profile. Int. Dairy J. 24:93-96. https://doi .org/10.1016/j.idairyj.2011.07.006.
Martini, M., F. Salari, and I. Altomonte. 2016. The macrostructure of milk lipids: The fat globules. Crit. Rev. Food Sci. Nutr. 56:12091221. https://doi.org/10.1080/10408398.2012.758626.

Mele, M., N. P. P. Macciotta, A. Cecchinato, G. Conte, S. Schiavon, and G. Bittante. 2016. Multivariate factor analysis of detailed milk fatty acid profile: Effects of dairy system, feeding, herd, parity, and stage of lactation. J. Dairy Sci. 99:9820-9833. https://doi.org/10 .3168/jds.2016-11451.

Ménard, O., S. Ahmad, F. Rousseau, V. Briard-Bion, F. Gaucheron, and C. Lopez. 2010. Buffalo vs. cow milk fat globules: Size distribution, zeta-potential, compositions in total fatty acids and in polar lipids from the milk fat globule membrane. Food Chem. 120:544-551. https://doi.org/10.1016/j.foodchem.2009.10.053.

Michalski, M. C., V. Briard, F. Michel, F. Tasson, and P. Poulain. 2005. Size distribution of fat globules in human colostrum, breast milk, and infant formula. J. Dairy Sci. 88:1927-1940. https://doi .org/10.3168/jds.S0022-0302(05)72868-X.

Michalski, M. C., M. Ollivon, V. Briard, N. Leconte, and C. Lopez. 2004. Native fat globules of different sizes selected from raw milk: Thermal and structural behavior. Chem. Phys. Lipids 132:247261. https://doi.org/10.1016/j.chemphyslip.2004.08.007.

Mootse, H., A. Pisponen, S. Pajumägi, A. Polikarpus, V. Tatar, A. Sats, and V. Poikalainen. 2014. Investigation of casein micelle particle size distribution in raw milk of Estonian Holstein dairy cows. Agron. Res. (Tartu) 12:153-158.

Murray, C. F., and K. E. Leslie. 2013. Newborn calf vitality: Risk factors, characteristics, assessment, resulting outcomes and strategies for improvement. Vet. J. 198:322-328. https://doi.org/10.1016/j .tvil.2013.06.007.

O'Callaghan, T. F., M. O'Donovan, J. P. Murphy, K. Sugrue, D. Mannion, W. P. McCarthy, M. Timlin, K. N. Kilcawley, R. M. Hickey, and J. T. Tobin. 2020. Evolution of the bovine milk fatty acid profile - From colostrum to milk five days post parturition. Int. Dairy J. 104:104655. https://doi.org/10.1016/j.idairyj.2020.104655.

Palmquist, D. L. 2006. Milk fat: Origin of fatty acids and influence of nutritional factors there on. Pages 43-92 in Advanced Dairy Chemistry, Volume 2: Lipids. P. F. Fox and P. L. H. McSweeney, ed. Springer.

Playford, R. J., and M. J. Weiser. 2021. Bovine colostrum: Its constituents and uses. Nutrients 13:265. https://doi.org/10.3390/ nu13010265.

Poppitt, S. D., G. F. Keogh, T. B. Mulvey, B. H. McArdle, A. K. MacGibbon, and G. J. Cooper. 2002. Lipid-lowering effects of a modified butter-fat: A controlled intervention trial in healthy man. Eur. J. Clin. Nutr. 56:64-71. https://doi.org/10.1038/sj.ejcn.1601282.

Przybylska, J., E. Albera, and M. Kankofer. 2007. Antioxidants in bovine colostrum. Reprod. Domest. Anim. 42:402-409. https://doi .org/10.1111/j.1439-0531.2006.00799.x.

Reh, W. A., E. A. Maga, N. M. B. Collette, A. Moyer, J. S. ConradBrink, S. J. Taylor, E. J. DePeters, S. Oppenheim, J. D. Rowe, R. H. BonDurant, G. B. Anderson, and J. D. Murray. 2004. Hot topic: Using a stearoyl-CoA desaturase transgene to alter milk fatty acid composition. J. Dairy Sci. 87:3510-3514. https://doi.org/10.3168/ jds.S0022-0302(04)73486-4.

Sangild, P. T. 2003. Uptake of colostral immunoglobulins by the compromised newborn farm animal. Acta Vet. Scand. Suppl. 98:105122. https://doi.org/10.1186/1751-0147-44-S1-S105.

Sats, A., T. Kaart, V. Poikalainen, A. Aare, L. Lepasalu, H. Andreson, and I. Jõudu. 2020. Bovine colostrum whey: Postpartum changes of particle size distribution and immunoglobulin G concentration at different filtration pore sizes. J. Dairy Sci. 103:6810-6819. https: //doi.org/10.3168/jds.2019-17604.

Singh, H., and S. Gallier. 2017. Nature's complex emulsion: The fat globules of milk. Food Hydrocoll. 68:81-89. https://doi.org/10 .1016/j.foodhyd.2016.10.011.

Uken, K. L., C. T. Schäff, L. Vogel, M. Gnott, D. Dannenberger, S. Görs, A. Tuchscherer, A. Tröscher, W. Liermann, and H. M. Hammon. 2021. Modulation of colostrum composition and fatty 
acid status in neonatal calves by maternal supplementation with essential fatty acids and conjugated linoleic acid starting in late lactation. J. Dairy Sci. 104:4950-4969. https://doi.org/10.3168/ jds.2020-19627.

Ulbricht, T. L. V., and D. A. T. Southgate. 1991. Coronary heart disease: Seven dietary factors. Lancet 338:985-992. https://doi.org/ 10.1016/0140-6736(91)91846-M.

Walter, L., S. Finch, B. Cullen, R. Fry, A. Logan, and B. J. Leury. 2019. The effect of physiological state, milk production traits and environmental conditions on milk fat globule size in cow's milk. J. Dairy Res. 86:454-460. https://doi.org/10.1017/ S0022029919000748.

Wiking, L., J. Stagsted, L. Björck, and J. H. Nielsen. 2004. Milk fat globule size is affected by fat production in dairy cows. Int. Dairy J. 14:909-913. https://doi.org/10.1016/j.idairyj.2004.03.005.

Yurchenko, S., A. Sats, V. Poikalainen, and A. Karus. 2016. Method for determination of fatty acids in bovine colostrum using GC-FID.
Food Chem. 212:117-122. https://doi.org/10.1016/j.foodchem .2016.05.103.

Yurchenko, S., A. Sats, V. Tatar, T. Kaart, H. Mootse, and I. Jõudu. 2018. Fatty acid profile of milk from Saanen and Swedish Landrace goats. Food Chem. 254:326-332. https://doi.org/10.1016/j .foodchem.2018.02.041.

\section{ORCIDS}

Andres Sats ํㅜ https://orcid.org/0000-0003-0047-2713

Tanel Kaart @ ittps://orcid.org/0000-0002-8936-768X

Liis Lutter @ https://orcid.org/0000-0002-4561-4052

Ivi Jõudu ำ https://orcid.org/0000-0003-2189-7884 